\title{
Enhancing Thai In-service Teachers' Perceptions of STEM Education with Tablet-based Professional Development
}

\author{
Sasithep Pitiporntapin ${ }^{1}$, Panuvit Chantara ${ }^{1}$, Wachira Srikoom ${ }^{2}$, Prasart Nuangchalerm ${ }^{3} \&$ Lisa M. Hines ${ }^{4}$ \\ ${ }^{1}$ Department of Education, Faculty of Education, Kasetsart University Bangkok, Thailand \\ ${ }^{2}$ The Institute for the Promotion of Teaching Science and Technology (IPST) Bangkok, Thailand \\ ${ }^{3}$ Department of Curriculum and Instruction, Faculty of Education, Mahasarakham University, Mahasarakham, \\ Thailand \\ ${ }^{4}$ Department of Biology, University of Colorado at Colorado Springs, Colorado, USA \\ Correspondence: Sasithep Pitiporntapin, Division of Science Education, Department of Education, Faculty of \\ Education, Kasetsart University, Bangkok, Thailand. Tel: 660-2579-7114 ext.161. E-mail: fedustp@ku.ac.th
}

Received: July 30, $2018 \quad$ Accepted: August 28, $2018 \quad$ Online Published: September 28, 2018

doi:10.5539/ass.v14n10p13

URL: https://doi.org/10.5539/ass.v14n10p13

\begin{abstract}
National efforts in Thailand are currently focused on promoting STEM (Science, Technology, Engineering, and Mathematics) education in order to better prepare the future generations to be an effective and productive workforce. In accordance with this mission, the goal of this research is to develop a tablet-based professional development (PD) program to enhance in-service teachers' perceptions of STEM education, which will directly affect both their decision to incorporate STEM, as well as their ability to effectively do so in their own classroom. To assess the efficacy of the PD program, we recruited 240 STEM and non-STEM teachers from basic education schools in Thailand to participate in the program. The activities in this program were divided into three parts: 1) increasing knowledge about STEM education, 2) providing demonstrations of STEM teaching, and 3) developing STEM-based lessons. Data were collected throughout the tablet-based PD program from focus group discussion sessions, pre-post questionnaires, and informal interviews. Data were analyzed using content analysis. The findings revealed that before participating in the tablet-based PD program, the majority of participants had limited knowledge on STEM education and were uncertain on how to integrate STEM into their instructional practices. They also had difficulty with connecting the different STEM disciplines in their activities. Although they were interested in implementing the STEM educational approach, they lacked confidence on how to accomplish this. After completing the tablet-based PD program, many participants had a much better understanding of STEM education and greater confidence with implementing STEM pedagogical approaches.
\end{abstract}

Keywords: STEM education, Tablet-based professional development, teachers' perceptions

\section{Introduction}

In Thailand, there are national efforts to transform society to a new economic model, known as the "Thailand 4.0" policy, which is focused on promoting creativity, innovation, new technology, and the availability of high-level services (Baxter, 2017). STEM education, a pedagogical approach that integrates Science, Technology, Engineering, and Mathematics, is considered a critical component to this transformation, as it provides the best opportunity to prepare the new generations of Thailand's workforce in several sectors, including industry, health services, environmental management, logistics, and transportation. The Thai government encourages all schools to implement STEM education into their curriculum, which should include project-based and problem-based learning activities that provide students the opportunity to solve problems in daily life, as well as challenge them to seek alternative solutions (Boonruang, 2015).

In addition, in-service teachers' strongly support the initiative to incorporate STEM education in their classrooms. Their perceptions and knowledge of the STEM approach are vital for the success of educational reform, since students' learning is directly related to their teachers' approaches to teaching (Trigwell, Prosser, \& Waterhouse, 1999). Currently, many pre-service teacher programs do not incorporate STEM training, and STEM concepts are often ambiguous among in-service teachers (Lederman \& Lederman, 2013). Furthermore, there are few general guidelines or models available for teachers to integrate STEM approaches in their classrooms. Consequently, 
there are some misconceptions regarding STEM education (Chulavatnatol, 2013). Srikoom \& Hanuscin (2017) found that the majority of the teachers in Thailand had very limited knowledge on STEM education, and some of them were unable to even interpret the definition of STEM education. To address these issues, PD programs in STEM are imperative for assuring teachers are prepared to effectively implement this educational reform.

According to the literature, an effective PD program should offer different forms of media for presentation and delivery of materials, as well as make training practical, relevant, hands-on, and interactive (Burgstahler, 2006). Furthermore, a successful PD program should be able to accommodate individual needs (Darling-Hammond \& Sykes, 1999), allow sufficient time, offer on-going professional support (Radford, 1998), and provide easy access to all the necessary resources (Loucks-Horsley et al., 2003). Gains in both knowledge and perception require time and persistence (Loucks-Horsley et al., 2003). The process of change can only occur when the teachers are confident about the outcomes of the teaching strategies (Bell, 1998). Teachers must recognize a need, make plans to address this need, actively engage in improvements, and allow sufficient time to evaluate the efficacy of the new practices (Boling \& Martin, 2005). Sikes (1992) suggested that in the change process, teachers are continually required to alter their administrative and organizational systems, their pedagogy, curriculum content, the resources and technology that they use, and their assessment procedures.

The use of technology for PD can provide teachers more opportunities to develop content knowledge, learn new pedagogies, deepen understanding of student thinking and learning, and enhance the utilization of varied teaching strategies (Loucks-Horsley et al., 2003). Tablet computers can be used as an effective tool for scaffolding learning and changing the learning environment (Melhuish \& Falloon, 2010) because it provides users or learners with access to a myriad of software choices due to the various apps available (Shuler, 2012). Additionally, Sauers \& McLeod (2011) reported that the use of the tablet computer could enhance teacher's engagement, develop cross-disciplinary knowledge, and enrich $21^{\text {st }}$ century skills. In addition, many educators agree that technology has great potential to improve education due to the capacity to support powerful and sophisticated learning environments (Hermans et al., 2008). Botha \& Herselman (2015) found that teachers change from standing in front of a classroom of students sitting in rows to a more dynamic learning environment where learners are engaged in group projects using tablet computers. However, there is minimal research on the use of tablet computers for PD. The majority of published studies on the use of tablet computers for education in Thailand are focused on student learning. Sritha, Techakosit, \& Patarathitinant (2003) found that using tablet computers helped students to better understand what they learned, and improved their motivation to participate in the classroom. However, poor quality of PC tablets, unstable internet accessibility, and the inability of teachers to directly control the technology were major concerns with this format. Therefore, this research is significant because it provides a model for institutes, schools, and universities on how to incorporate the use of tablet computers for PD and offers practical guidelines that will enhance in-service teachers' perceptions of STEM education.

\section{Research Objectives and Questions}

The objective of this research was to enhance perception of STEM education among in-services teachers across Northern, Northeastern, Central, and Southern Thailand using a tablet-based PD program. The overarching research question is: "What changes in teachers' perceptions of STEM education occurred as a result of participating in the tablet-based PD program?"

\section{Research Methodology}

To investigate in-service teachers' perceptions of STEM education regarding the definition of STEM education, the disciplines within STEM education, STEM integration, and implementation of STEM education in their classroom, the researchers used an interpretive paradigm that attempts to understand and explain human and social reality (Crotty, 1998). This study seeks to identify how teacher perceptions of STEM education were affected as a result of participating in the tablet-based PD program.

\subsection{Context of the Study}

This study involved the development of a new tablet-based PD program to enhance teacher knowledge of STEM education in order to promote educational reform among in-service teachers. This program was designed within a Thai context, and builds upon prior knowledge while promoting the construction of new knowledge (Bell, 1998). The program included many additional features, such as the opportunity for teachers to reflect on their practices (Richardson \& Placier, 2001), a follow-up phase to assess their progress (Fetters et al., 2002), activities that were relevant to the classroom (Loucks-Horsley et al., 2003), and multiple strategies for teacher development (Loucks-Horsley et al., 2003). While participating in the tablet-based PD program, they were asked to enroll in the iTunes University (iTunes U) program called "iPad for STEM" and participate in various 
activities such as discussion, presentation, self-reflection, hands-on activities, interviews, and the sharing of ideas with guest speakers.

The tablet-based PD program comprises three main parts. In part I, in-service teachers were given an introduction of STEM education during a one-day meeting. The content included: 1) the definition of STEM education, 2) the importance of STEM education, 3) the role of technology in STEM education, 4) and teaching strategies in STEM education. Part II involved three demonstrations of STEM education that utilize the application of the iPad (tablet computer) for learning: Tall tower challenge with the application "Book creator"; Edible car with "Keynote"; and "Oil spill with "iMovie". In Part III, in-service teachers were asked to develop lesson plans in STEM education that integrate the iPad as a learning tool. The researchers developed this PD program. Prior to implementation during January-April 2017, the contents of the PD program were reviewed by three external experts, which included a scientist, a science educator, and an expert teacher. During this study, the role of the researcher was to act as a facilitator to clarify any points that the participants did not understand. Typically, this in-service teachers' discussion took at least one hour per meeting with the teachers.

\subsection{Research Participants}

The research participants in this study were 240 in-service teachers from 50 public schools under the Office of the Basic Education Commission (OBEC) in Thailand during the 2017 academic year. The participants comprised primary and secondary teachers, between 23-55 years old, who taught either science, mathematics, computer science, and English. The majority came from Northern, Northeastern, Central, and Southern parts of Thailand. Participants were selected using purposive sampling based on three criteria: (1) willingness to participate in the tablet-based PD program, (2) interest in STEM education, and (3) ability to participate in the tablet-based program anytime.

\subsection{Data Collection and Analysis}

Data were collected using different methods at various times throughout the study. At the beginning of implementation of the tablet-based PD program, they were asked to enroll in the iTunes U program called "iPad for STEM" and complete an open-ended questionnaire that assesses their prior knowledge about STEM education. The questions included the definition of STEM education, their perceptions of each discipline in STEM education, STEM integration, and implementation of STEM education in their classroom.

During the program, the researchers asked participants to study the lessons provided in iTunes U. They had to work in groups of four-five to complete the assigned tasks in each lesson. After that, they completed each assignment, the researchers asked them to present their assignments and discuss their perceptions regarding STEM education. At the end of the program, all of them were asked to complete the same open-ended questionnaire that they completed at the beginning of the study. In addition, the researchers conducted group discussions during the tablet-based PD program to examine changes in their perceptions of STEM education. The researchers also used an informal 25-30 minute interview to clarify some points that the researchers did not understand. Oral consent was requested from all participants in order to take part in the research. Anonymity was preserved by assigning identification numbers to the participants after the data were collected.

For data analysis, the comparisons between the pre-test and post-test results were presented, in order to evaluate the influence of the intervention. The researchers used content analysis to analyze teachers' responses on the questionnaires, group discussions, and informal interviews in order to assess the overall impact of the tablet-based PD program on teacher perception of STEM education. The researchers had to read raw data for interpreting and constructing categories to capture relevant characteristics of the content.

\section{Findings}

Researchers found that Thai in-service teacher' perceptions of STEM education did change as a result of the tablet-based PD program. Here, we present a summary of their perceptions prior to and after completing the program on the definition of STEM education, the different disciplines in STEM education, STEM integration, and implementation of STEM education in the classroom.

\subsection{STEM Definition}

At the beginning of the tablet-based PD program, teachers were asked to define STEM education in their own words. Most of them had a partial understanding of STEM education. The majority of participants (201 teachers) viewed STEM education as simply a teaching approach that integrates several subjects. For example, one teacher stated, "It is a very interesting teaching approach that integrates four subjects together Science, Technology, Engineering, and Mathematics". With respect to the benefits of STEM education, some teachers (25 teachers) mentioned $21^{\text {st }}$ century skills, as reflected in this comment, "STEM education is a new teaching approach for 
promoting students' essential skills in the $21^{\text {st }}$ century, such as problem solving, collaboration, creative thinking, and so on".

However, there were few of them (14 teachers) that did not answer several questions on the questionnaire. Informal interviews revealed that they did not know exactly what STEM education meant, as one stated, "I have heard about STEM education, but I do not know what it is about". These responses demonstrated that they lacked even a basic understanding of the STEM education approach.

By participating in the tablet-based PD program, they had the opportunity to learn the definition of STEM education from video clips produced by the Institution for Promotion of Teaching Science and Technology (IPST), which is an organization to drive STEM education for teaching and learning in Thailand. It defined STEM education as "an approach that integrates science, engineering, technology, and mathematics, with a focus on solving real-life problems, including the development of new processes or products that benefit human life and work".

After participation in the PD program, only one teacher skipped the question regarding the definition of STEM education. Most of them (190 teachers) perceived that STEM education is an integrated teaching approach, but they were only able to identify different aspects of this pedagogical approach, such as promoting students' application of knowledge. For example, a teacher commented, "STEM education is for promoting students' to apply their knowledge in order to solve a problem".

Similarly, some of them (30 teachers) viewed that their students will get a better understanding of concepts related to real-life situations. As reflected in this comment, "Because STEM is related to real-life situations, students can learn the concepts behind the learning activities". Moreover, few of them (20 teachers) also pointed out that STEM education involves project-based learning. One participant commented, "Students learn to work together in groups to do a project that incorporates Science, Technology, Engineering, and Mathematics".

\subsection{Science}

When we asked teachers about what science in STEM education is, most of them (102 teachers) focused on science as content for students to learn. For example, one participant stated, "Students have to learn basic science content integrated with other subjects in STEM education in order to have the ability to create new things".

Some teachers ( 88 teachers) pointed out that science in STEM education is related to experiments. One teacher commented, "I think that experimentation is the main part of science in STEM education". Few of them (50 teachers) focused on the science process skills. Another teacher commented, "In STEM education, science process skills have to be used to explain something or create new knowledge". However, no one indicated the relation of science to other disciplines in STEM education, demonstrating that their perceptions were limited to a single STEM discipline.

To cope with this problem, they were asked to think from a student's view (as a learner) and reflect about the nature of science after completing each STEM activity. They seemed to have a better understanding of what science represents in STEM education. After participating in the tablet-based PD program, all of them (240 teachers) mentioned that teaching science should be focused more on developing scientific process skills' rather than the understanding of scientific concepts. Moreover, they knew the relationship between science and other subjects in STEM education.

For example, one participant stated, "Science in STEM education is related to Technology, Engineering, and Mathematics. Science helps with technology development. In turn, technology helps to provide new knowledge in science. For engineering, science is used in the engineering process to create new technology. Lastly, mathematics is used in science".

\subsection{Technology}

Most of them (199 teachers) recognized that the " $T$ " in STEM stands for technology, which is related to applying science and other subjects to create new inventions or products. One teacher stated, " $T$ is Technology. Technology comes from applying other subjects to create new inventions or products to simplify our life". However, there were some misconceptions about what technology means in STEM education. Some of them (25 teachers) thought that technology is simply a craft. For example, one participant commented, "I think that a craft that students can do step-by-step is related to technology in STEM education because it is about creating something new".

In addition, few participants (15 teachers) pointed that technology in STEM education involves using a computer 
or iPad. For example, one teacher stated, "Technology in STEM involves the use of a computer or iPad to search for information when doing a presentation". There were a few teachers (5 teachers) who did not provide any ideas about technology in STEM education.

While participating in various activities in the PD program, they had a lot of opportunities to see many kinds of technology that could be used in STEM activities, as well as have discussions about the nature of technology. Consequently after participation in the tablet-based PD program, most of them (223 teachers) replied that technology in STEM education is not simply limited to a new invention or product, or the use of a computer to search information. Furthermore, some of them mentioned technology in terms of a new process. One of the participants defined technology as "inventing a new process to solve a problem or create new things". A few teachers (17 teachers) pointed out that using technology itself to create innovation. Another teacher stated, "We can describe technology in STEM as using technology, such as tools to create new products or processes for responding to human needs".

\subsection{Engineering}

Initially, most of the teachers (123 teachers) in the tablet-based PD program perceived that engineering in STEM education only involves coming up with a design. For example, one teacher stated, "Engineering is concerned with creating designs to build new things". Some of them (102 teachers) thought that engineering is about building the item. Another teacher commented, "In STEM education, engineering is about building or construction". Surprisingly, some of them (15 teachers) believed that the word " $E$ " in STEM education stands for "English" instead of "Engineering". As stated by one participant, "From my understanding, E in STEM education is about linking English with other subjects".

During the focus group discussions, some revealed that they did not expect engineering to be included in primary and secondary education. One participant stated, "I did not think that primary and secondary students would be learning about engineering. Engineering is in the University, so I think the " $E$ " should represent English in STEM Education". In addition, there were concerns about teaching engineering in their classroom. One participant stated, "I have never taught engineering before, and I think that it will be difficult for my students".

During the PD program, they learned about the engineering design process and applied this process to solve a problem in given situations. Afterward, most of the participants (134 teachers) changed their perceptions about the engineering design process, which is composed of defining the problem, planning a solution, making a model, testing the model, reflecting and redesigning. Their changed perception was reflected in their responses to the questionnaire.

One participant commented, "Engineering in STEM education relates to the process of discovering a solution to a problem. Many times the solution is concerned with designing a product. The process is like a cycle that starts with defining the problem, seeking a solution, coming up with a model, testing the model, and then going back to an earlier step to make a modification or change to your design". However, more than half of participants (106 teachers) stills perceived that engineering is just about creating designs to build new things.

\subsection{Mathematics}

At the beginning of the tablet-based PD program, most teachers (168 teachers) had perceived mathematics as solely applying quantitative methods; "Mathematics is about numbers, counting, calculations, and measurement". In addition, some of them (53 teachers) also talked about structure; "Mathematics in STEM education is concerned with the shapes and motions of physical objects".

For discussion, they also pointed out that they always ask their students to measure different shapes when designing something; "We apply mathematics in my class to measure different shapes when they design something". In the tablet-based PD program, they had chance to reflect on the application of mathematics in the provided STEM activities. After participation in the program, the majority of teachers (222 teachers) recognized that mathematics is more than just doing various operations. For example, one participant stated, "Mathematics is about thinking and reasoning, logic, and solving problems".

Another participant commented, "Mathematics also relates to patterns, for example, the door and window of a house have similar patterns. All leaves of the same tree have similar patterns of shape". In addition, few of them (18 teachers) pointed out the relation between mathematics and others subjects in STEM education, as reflected in this comment, "Mathematics is used in science, technology and engineering".

\subsection{STEM Integration}

Before participating in the tablet-based PD program, the majority of teachers (230 teachers) indicated that STEM 
education is a teaching approach that integrates four subject matters: Science, Technology, Engineering, and Mathematics as a transdisciplinary course or program. For example, one participant stated, "STEM is an integrated teaching approach that mixes up all STEM disciplines". However, some had limited knowledge. Another participant commented, "I only know that there are four subject matters: Science, Technology, Engineering, and Mathematics that are integrated into the content that we are teaching".

In addition, there were some teachers (12 teachers) who thought that STEM education represented any single discipline within STEM, as illustrated in this comment, "STEM education is a teaching approach in science subject that is linked with Technology, Engineering, and Mathematics for promoting students' $21^{\text {st }}$ century skills, such as creativity and innovation, collaborative working, communication skills, and so on". Furthermore, there were a few teachers (8 teachers) who did not provide any definition for STEM education. While participating in the tablet-based program, the participants engaged in several activities that provided examples of STEM integration. They also got direct experiences through role-playing as students in some activities. Consequently, most of them (178 teachers) discovered that STEM Integration was not strictly limited to a transdisciplinary course or a single disciplinary integration.

They were able to make connections between all the STEM disciplines, as reflected in this comment, "STEM is both $\mathrm{t}$ science and math teaching approach that is also connected with concepts of technology and engineering". In addition, some teachers (62 teachers) also mentioned the complementary overlapping across disciplines, as reflected in this comment, "STEM is a teaching approach that teaches science, technology, engineering, and math together within a specific theme". These perceptions were demonstrated again during the discussion after completing the tablet-based PD program. Overall, the participants had a better understanding of how to integrate STEM education in their classroom.

\subsection{Implementation of STEM Education}

Before participating in the tablet-based PD program, we asked teachers about their confidence with implementing STEM education in their classroom, the majority of teachers (175 teachers) pointed that they were interested in STEM education because they thought that there are many benefits for their students. However, some of them (50 teachers) were concerned with how to integrate STEM education in their classroom. Specifically, they indicated that they did not know how to bring engineering into their lessons. One teacher commented, "I have never used engineering in my class. I really do not know how to design my instruction". In addition, few teachers ( 8 teachers) also were concerned about the amount of time for science, technology, engineering and mathematics in their lesson, as reflected in this comment, "I am worried about the time for teaching because it is limited. If I put STEM education in my lesson, I think that it will take too much class time".

Moreover, they (7 teachers) felt that they needed some support from their school. One teacher commented, "The government is focused on Thailand 4.0, so the school has to improve the curriculum so that it includes STEM education. But in my school, there is not enough equipment for students to do STEM activities". After participation in the tablet-based program, many of the participants (190 teachers) gained more confidence on how to apply STEM education in their classrooms. One teacher stated, "Now, I know how to design a STEM lesson, especially using the engineering process. I am quite sure that I will apply it in my classroom".

Some of them (28 teachers) reflected on the benefits that their students will get from a STEM lesson. For example, one teacher commented, "I think that STEM education is good for my students. My students are more interested in science. There are many applications on the iPad such as iMovie, Book creator, Keynote that students can use while doing activities, and gain a lot of knowledge and skills". However, few teachers (20 teachers) are still concerned about time for STEM instruction. One commented, "There are many activities in school, so bringing STEM into my lessons will require some thought on how to include such a time demanding activity." In addition, a few teachers (2 teachers) also commented on media and materials. One stated, "There is a limited number of iPads for my students, and I have to use them carefully. As the teacher, I have to know how to update it, maintain it, and repair it".

\section{Conclusions and Discussion}

The findings of this study revealed that many in-service teachers held limited knowledge of STEM education before participating in the tablet-based PD program. Some could not provide a definition of STEM education, while others were inconsistent with the definition from IPST (2013), which defines STEM education as an approach that integrates science, engineering, technology, and mathematics, with a focus on solving real-life problems, including the development of new processes or products that benefit human life and work. These perceptions may have affected their previous experiences. Moreover, most of them seemed to view each STEM discipline separately as Bybee (2013) proposed, where STEM equals a quartet of separate disciplines with no 
explicit connection among them. This can represent a course that provides general content of the STEM disciplines or four separate courses, one for each discipline. Most of them did not know how to integrate STEM in their instruction and could not connect the disciplines. Furthermore, they had limited knowledge within each of the STEM disciplines.

After participation in the tablet-based PD program, they resolved many of these issues. In the dimension of implication of STEM education in classroom, this research demonstrated that even if they had a strong desire to implement STEM education in their classroom, they still had concerns, especially with engineering. Many scholars agree that integrating engineering concepts into the lesson plan is a challenge for many science teachers (Haag \& Megowan, 2015). Consequently, teachers with negative attitudes about STEM education will tend to avoid teaching STEM (Appleton, 2003). However, after participating in the tablet-based PD program, many teachers were more knowledgeable on the different ways to integrate STEM, and they were also more confident about doing so in their classroom. Research suggests that teacher confidence is an important predictor of ability for teaching STEM-related content, and teachers that tend to have problems with content, especially engineering, can have a negative influence on student learning (Harlen \& Holroyd, 1997; Jarrett, 1999; Ford, 2007). The changes in teacher perceptions of STEM as a result of participating in the PD program are likely to enhance STEM education in the classroom (Nuangchalerm, 2018). Furthermore, the use of tablets could have greatly facilitated the impact of the PD program. Technology has great potential to improve education due to the capacity to support powerful and sophisticated learning environments (Hermans et al., 2008).

\section{Recommendations}

These findings demonstrate that a tablet-based PD program can enhance and promote teacher perception and understanding of STEM education. However, the researchers need to continue to follow-up on the participants in this tablet-based PD program to ultimately assess the impact of this program on student learning outcomes. Based on the substantial impact that this program had on the participants, we encourage teachers, administrators, professional programs and science educators to adopt or adapt this program or this professional framework in order to improve teaching practices. We also encourage them to apply this sort of technology to promote the acquisition of $21^{\text {st }}$-century skills among the next generation of students. In addition, policy makers and stakeholders need to invest in the development of adequate infrastructure and available resources to support the use of new technologies in the classroom.

\section{References}

Appleton, K. (2003). How do beginning primary school teachers cope with science? Toward an understanding of science teaching practice. Research in Science Education, 33(1), 1-25. https://doi.org/10.1023/A:1023666618800

Baxter, W. (2017). Thailand 4.0 and the future of work in the Kingdom. International Labour Organization. Retrieved from http://tinyurl.com/mkhf5r5

Bell, B. (1998). Teacher development in science education. In B. J. Fraser, \& K. G. Tobin (Eds.), International Handbook of Science Education (pp. 681-693). Great Britain: Kluwer Academic Publishers.

Boling, C., \& Martin, S. (2005). Supporting teacher change through online professional development. The Journal of Educators Online, 2(1), 1-15. https://doi.org/10.9743/JEO.2005.1.1

Boonruang, S. (2015). A STEM education: New method of teaching science, technology, engineering and mathematics in an applied approach is being promoted by IPST. Retrieved from http://www.bangkokpost.com

Botha, A., \& Herselman, M. (2015). Supporting teacher professional development to use tablets in resource constrained schools: A case study of Cofimvaba schools, Eastern Cape Province, South Africa. Journal on Systemics, Cybernetics and Informatics, 13(5), 20-27.

Burgstahler, S. (2006). Equal access: Universal design of instruction. Seattle: University of Washington.

Bybee, R. (2013). The case for STEM education: Challenges and opportunities. NSTA press.

Chulavatnatol, M. (2013). Conceptual framework document: Science, Technology, Engineering, and Mathematics education: STEM education. Journal of Science Teacher Association of Thailand, 19, 3-14.

Crotty, M. (1998). The Foundations of Social Research: Meaning and Perspective in the Research Process. Australia: Allen \& Unwin.

Darling-Hammond, L., \& McLaughlin, M. W. (1995). Policies that support professional development in an era of 
reform. Phi Delta Kappan, 76(8), 597-604. https://doi.org/10.1177/003172171109200622

Ford, B. A. (2007). Teaching and learning: Novice teachers' descriptions of their confidence to teach science content. Doctoral dissertation Georgia State University. Retrieved form https://scholarworks.gsu.edu/ cgi/viewcontent.cgi?referer=https://scholar.google.co.th/\&httpsredir=1\&article=1020\&context=msit_diss

Haag, S., \& Megowan, C. (2015). Next generation science standards: A national mixed-methods study on teacher readiness. School Science and Mathematics, 115 (8), 416-426. https://doi.org/10.1111/ssm.12145

Harlen, W. (1997). Primary Teachers understanding in science and its impact in the classroom. Research in Science Education, 27(3), 323-337. https://doi.org/10.1007/bf02461757

Hermans, R., Tondeur, J., Van Braak, J., \& Valcke, M. (2008). The impact of primary school teachers' educational beliefs on the classroom use of computers. Computers \& Education, 51(4), 1499-1509. https://doi.org/10.1016/j.compedu.2008.02.001

Jarrett, O. S. (1999). Science interest and confidence among preservice elementary teachers. Journal of Elementary Science Education, 11, 47-57. https://doi.org/10.1007/BF03173790

Lederman, N. G., \& Lederman, J. S. (2013). Is it STEM or "S \& M" that we truly love?. Journal of Science Teacher Education, 24(8), 1237. https://doi.org/10.1007/s10972-013-9370-z

Loucks-Horseley, S., Love, N., Stiles, K. E., Mundry, S., \& Hewson, P. W. (2003). Designing Professional Development for Teachers of Science and Mathematics. The National Institute for Science Education. California: Corwin Press.

Melhuish, K., \& Falloon, G. (2010). Looking to the future: M-learning with the i-Pad. Computers in New Zealand Schools, 22(3), 1-16.

Nuangchalerm, P. (2018). Investigating views of STEM primary teachers on STEM education. Chemistry: Bulgarian Journal of Science Education, 27(2), 208-215.

Sauers, N. J., \& McLeod, S. (2011). What does the research say about school one-to-one computing initiatives? Retrieved June 12, 2017, from http://www.natickps.org/CASTLEBrief01_LaptopPrograms.pdf

Shuler, C. (2012). iLearning II: An analysis of the education category of the iTunes App store. New York: The Joan Ganz Cooney Center at Sesame Workshop.

Sikes, J. P. (1992). Imposed change and the experienced teacher. In M. Fullan, \& A. Hargreaves (Eds.), Teacher Development and Educational Change (pp. 36-55). London and Washington DC: The Falmer Press.

Srikoom, W., Hanusin, D., \& Faikhamta, C. (2017). Perceptions of in-service teachers toward teaching STEM in Thailand. Asia-Pacific Forum on Science Learning and Teaching, 18(2), 1-23.

Sritha, S., Techakosit, S., \& Patarathitinant, S. (2003). Learning management results on the topic of electricity via the educational digital content system using PC tablets with grade 9 students. Silpakorn University Journal, 35(3), 71-90.

The Institute for the Promotion of Teaching Science and Technology (IPST). (2013). STEM education in $\begin{array}{lllll}\text { Thailand. } & \text { Retrieved } & \text { July } & \text { 2017, }\end{array}$ http://dpst.apply.ipst.ac.th/specialproject/index.php/menu-styles/stemthailand

Trigwell, K., Prosser, M., \& Waterhouse, F. (1999). Relations between teachers' approaches to teaching and students' approaches to learning. Higher Education, 37, 57-70. https://doi.org/10.1023/A:1003548313194

\section{Copyrights}

Copyright for this article is retained by the author(s), with first publication rights granted to the journal.

This is an open-access article distributed under the terms and conditions of the Creative Commons Attribution license (http://creativecommons.org/licenses/by/4.0/). 